\title{
TU/e EmonOWEN

\section{Quiescent crystallization of poly(lactic acid) studied by optical microscopy and light-scattering techniques}

\section{Citation for published version (APA):}

Lohmeijer, P. J. A., Goossens, J. G. P., \& Peters, G. W. M. (2017). Quiescent crystallization of poly(lactic acid) studied by optical microscopy and light-scattering techniques. Journal of Applied Polymer Science, 134(10), 1-9. [44566]. https://doi.org/10.1002/app.44566

\section{Document license:}

TAVERNE

DOI:

10.1002/app.44566

Document status and date:

Published: 10/03/2017

\section{Document Version:}

Publisher's PDF, also known as Version of Record (includes final page, issue and volume numbers)

\section{Please check the document version of this publication:}

- A submitted manuscript is the version of the article upon submission and before peer-review. There can be important differences between the submitted version and the official published version of record. People interested in the research are advised to contact the author for the final version of the publication, or visit the $\mathrm{DOI}$ to the publisher's website.

- The final author version and the galley proof are versions of the publication after peer review.

- The final published version features the final layout of the paper including the volume, issue and page numbers.

Link to publication

\section{General rights}

Copyright and moral rights for the publications made accessible in the public portal are retained by the authors and/or other copyright owners and it is a condition of accessing publications that users recognise and abide by the legal requirements associated with these rights.

- Users may download and print one copy of any publication from the public portal for the purpose of private study or research.

- You may not further distribute the material or use it for any profit-making activity or commercial gain

- You may freely distribute the URL identifying the publication in the public portal.

If the publication is distributed under the terms of Article 25fa of the Dutch Copyright Act, indicated by the "Taverne" license above, please follow below link for the End User Agreement:

www.tue.nl/taverne

Take down policy

If you believe that this document breaches copyright please contact us at:

openaccess@tue.nl

providing details and we will investigate your claim. 


\title{
Applied Polymer
}

\section{Quiescent crystallization of poly(lactic acid) studied by optical microscopy and light-scattering techniques}

\author{
P. J. A. Lohmeijer, ${ }^{1}$ J. G. P. Goossens, ${ }^{1}$ G. W. M. Peters ${ }^{2}$ \\ ${ }^{1}$ Department of Chemical Engineering and Chemistry, Eindhoven University of Technology, P.O. Box 513, 5600 MB, \\ Eindhoven, The Netherlands \\ 2Department of Mechanical Engineering, Eindhoven University of Technology, P.O. Box 513, 5600 MB, Eindhoven, \\ The Netherlands \\ Correspondence to: G.W. M. Peters (E-mail: g.w.m.peters@tue.nl)
}

\begin{abstract}
The crystallization behavior of poly(lactic acid) (PLA) has been studied extensively, and this has resulted in different reported values for the nucleation densities (Ns) and crystal growth rates (Gs) for similar grades. These inconsistencies may be magnified when they are used in subsequent modeling studies. Therefore, the quiescent crystallization behaviors of three PLA grades were studied with polarized optical microscopy and small-angle light-scattering experiments. The Gs and Ns were determined at several isothermal crystallization temperatures with a device that provided near-instantaneous cooling to the isothermal crystallization temperature. Two growth rate regimes, which were attributed to $\alpha$ and $\alpha^{\prime}$ crystallization with a transition around $120^{\circ} \mathrm{C}$, were observed. Avrami analysis revealed that the poly(L-lactic acid) homopolymer crystal growth was three-dimensional and was unaffected by the presence of stereocomplex PLA. The PLA copolymer crystals had a transition from an initial sheaflike conformation to threedimensional growth. Furthermore, the lamellar twisting of the homopolymer was observed at the isothermal crystallization temperature around $144^{\circ} \mathrm{C}$. These findings can be used for future modeling studies to predict material behavior in various industrial processes. (c) 2016 Wiley Periodicals, Inc. J. Appl. Polym. Sci. 2017, 134, 44566.
\end{abstract}

KEYWORDS: biocompatibility; copolymers; crystallization

Received 19 April 2016; accepted 10 October 2016

DOI: 10.1002/app.44566

\section{INTRODUCTION}

In recent years, poly(lactic acid) (PLA) has been established as one of the most commercially viable biobased polymers. ${ }^{1-3}$ Its highlighted features often include sustainability, biodegradability, and biocompatibility-resorbability, even though the processability of PLA has its complications. The material is sensitive to moisture and is, thus, prone to hydrolysis. It is also susceptible to thermal degradation during melt processing. ${ }^{4,5}$ The inherent slow crystallization rate implies that the final product will most likely be amorphous; this has a large impact on the thermal stability, barrier properties, and final mechanical properties of the polymer. Therefore, efforts to circumvent these problems are very relevant, with published studies covering a broad range of approaches, including the addition of nucleating agents, plasticization, and the application of strain-enhanced crystallization. $^{6-12}$ The examination of the resulting properties was outside the scope of this study.

A complicating factor in the understanding and description of the crystallization behavior of PLA is that the material displays crystal polymorphism. The most stable crystal form is the $\alpha$ crystal structure, which has a pseudo-orthorhombic unit cell ( $[a=10.7 \AA, b=6.45 \AA, c=27.8 \AA$; a, b and c are the lattice constants of a orthorhombic unit cell]) with a $10_{3}$ helical conformation; it is most commonly found during crystallization from the melt or dilute solutions. ${ }^{13}$ The $\alpha^{\prime}$ form is similar to the $\alpha$ form, but it shows a more disordered type of crystal packing. This form is obtained during the crystallization of PLA at temperatures below $120^{\circ} \mathrm{C}$.

PLA also exhibits a $\beta$ form, which has an orthorhombic unit cell ( $a=10.31 \AA, b=18.21 \AA, c=9.0 \AA$ ) with an extended 3 helical conformation. It is only observed when PLA is crystallized at high temperatures and high draw ratios. ${ }^{14}$ Moreover, the $\gamma$ modification of PLA was found during epitaxial crystallization on hexamethylbenzene. ${ }^{15}$ More recently, a mesophase for PLA was described by Stoclet et al. ${ }^{16}$; it was observed upon solid-state drawing just above the glass-transition temperature $\left(T_{g}\right)$.

Furthermore, because the lactic acid monomer from which PLA is derived contains a stereocenter, a wide range of different 
chain architectures can be produced. The pure poly(L-lactic acid) (PLLA) homopolymer, containing only L-lactic acid monomer units, is a crystalline and stiff material. Increasing the D-lactic acid content in the main chain of a random poly(L,Dlactic acid) copolymer decreases its crystallization rate, melting temperature $\left(T_{m}\right)$, and stiffness. ${ }^{17}$ The optically pure enantiomers PLLA and poly(D-lactic acid) (PDLA) can also cocrystallize and form stereocomplex PLA, which has a much higher $T_{m}$, that is, $230{ }^{\circ} \mathrm{C} .{ }^{18}$ Tuning the processing conditions via the molecular weight distribution and PLLA/PDLA ratio allows one to control the extent of stereocomplex formation. When only a small amount of stereocomplex is formed within a PLLA matrix, the stereocomplex crystallites act as nucleating sites for the crystallization of the PLLA homopolymer. ${ }^{19,20}$

This vast array of possibilities in the PLA family provides many opportunities to study the crystallization behavior of PLA, as indicated earlier. However, the breadth of the PLA family also means that some variations exist in the reported values for the nucleation densities (Ns) and crystal growth rates (Gs) of ostensibly identical grades because of differences in the (i.a. = inter alia) molecular weights, polymerization methods, purification methods, and optical purities of the PLA polymers used. ${ }^{21}$ Moreover, the methods to obtain these values are not always well defined or otherwise employ limited cooling rates to reach a certain crystallization temperature from the melt state; this risks the onset of crystallization occurring during the cooling step. Such inaccuracies may be detrimental to subsequent modeling studies aimed at predicting material behaviors in various industrial processes.

Hence, in this study, we focused on the detailed characterization of the crystallization kinetics of three materials selected from the spectrum of the PLA family: a PLLA homopolymer, a PLA random copolymer, and a PLLA homopolymer blended with a small amount of PDLA to form a stereocomplex PLA to act as a nucleating agent for the homopolymer. These materials were quiescently crystallized from the melt state to determine their respective Ns and Gs with a Linkam dual-hot-stage device to provide near-instantaneous cooling to the different isothermal crystallization temperature $\left(T_{\text {iso }}\right)$ values. To this end, optical microscopy and light-scattering techniques were used to study the crystallization on the microscale, whereas X-ray diffraction was used to characterize the crystal structures on the nanoscale. Additionally, differential scanning calorimetry (DSC) was used to elucidate the crystal growth mechanism for each material.

\section{EXPERIMENTAL}

\section{Materials}

Three different PLA grades, kindly supplied by Synbra Technology, were studied. The first material was a PLLA homopolymer polymerized solely with L-lactic acid units; it had a weightaverage molecular weight $\left(M_{w}\right)$ of $144 \mathrm{~kg} / \mathrm{mol}$, a polydispersity index (PDI) of 1.6 , and a $T_{m}$ of $178^{\circ} \mathrm{C}$. The second material was a random copolymer of PLA containing approximately 5 mol \% of D-lactic acid units in the main chain, with an $M_{w}$ of $184 \mathrm{~kg} / \mathrm{mol}$, a PDI of 1.6 , and a $T_{m}$ of $149^{\circ} \mathrm{C}$. As the third material, the aforementioned PLLA homopolymer was compounded with 1 wt $\%$ PDLA homopolymer $\left(M_{w}=112 \mathrm{~kg} / \mathrm{mol}\right.$,

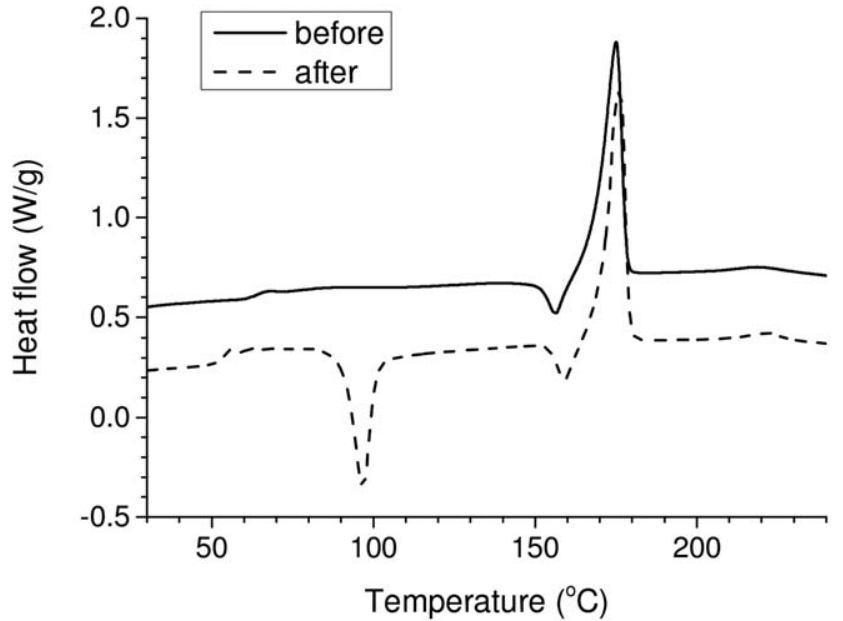

Figure 1. DSC thermograms of PLLA/1 wt \% PDLA before and after melting at $210^{\circ} \mathrm{C}$.

$\mathrm{PDI}=1.5)$ on a twin-screw extruder to form a stereocomplex PLA, which acted as a nucleating agent for PLLA.

The $T_{m}$ s were measured with a TA Instruments Q1000 differential scanning calorimeter at a constant heating rate of $10^{\circ} \mathrm{C} /$ min. The reported molecular weights were measured by size exclusion chromatography with hexafluoroisopropanol as the eluent and calculated against poly(methyl methacrylate) standards. Before use, all of the materials were dried at $60{ }^{\circ} \mathrm{C}$ overnight in a vacuum oven.

\section{Preparation}

We prepared the samples by melting a small amount of material between two microscope glass covers diameter $(\varnothing)=8 \mathrm{~mm}$; this resulted in a sample thickness of approximately $30 \mu \mathrm{m}$. Each sample was isothermally crystallized with a dual hot stage (Linkam JHT350). One hot stage was set to $210^{\circ} \mathrm{C}$ [PLLA equilibrium melting temperature $\left.\left(T_{m}^{0}\right)=207^{\circ} \mathrm{C}^{22}\right]$ to erase the thermal history of the homopolymer and retain any stereocomplex PLA crystals. Figure 1 shows that the melting peak of the stereocomplex PLA around $220^{\circ} \mathrm{C}$ was present in the material before and after melting at $210^{\circ} \mathrm{C}$.

The other hot stage was set to a certain $T_{\text {iso }}$, which was varied between $T_{g}\left(55^{\circ} \mathrm{C}\right)$ and $T_{m}$ for each material, with increments of $5^{\circ} \mathrm{C}$. The sample holder of the Linkam unit could be moved from one hot stage to the other pneumatically; this provided nearinstantaneous cooling to $T_{\text {iso }}$ and, thus, eliminated the possibility of crystallization onset during the cooling step even at large undercooling temperatures. A hole in the center of the hot stage $(\varnothing=$ $1 \mathrm{~mm}$ ) allowed for in situ measurements with polarized optical microscopy (POM) and small-angle light scattering (SALS).

\section{Characterization}

Optical micrographs of the samples crystallized in the Linkam JHT350 were taken with a Zeiss LM Axioplan optical microscope equipped with a Zeiss Axiocam camera in polarized transmission mode with a magnification of 12.5 or $40 \times$.

SALS measurements were carried out with a $1-\mathrm{mW}$ intensitystabilized HeNe laser $(\lambda=633 \mathrm{~nm})$ as the incident light source. 


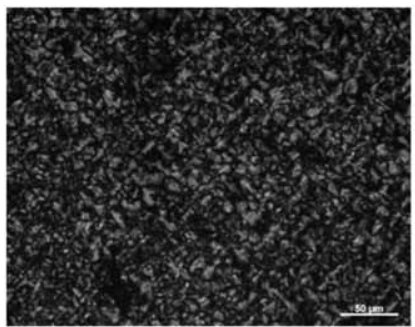

$T_{\text {iso }}=110^{\circ} \mathrm{C}, t_{\text {iso }}=3 \mathrm{~min}$

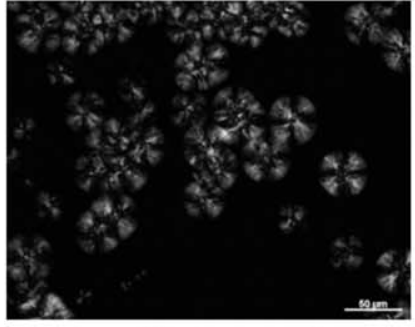

$T_{\text {iso }}=130^{\circ} \mathrm{C}, t_{\text {iso }}=5 \mathrm{~min}$

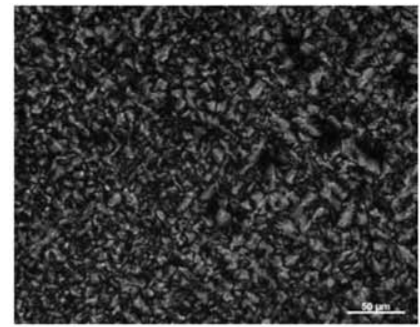

$T_{\text {iso }}=115^{\circ} \mathrm{C}, t_{\text {iso }}=3 \mathrm{~min}$

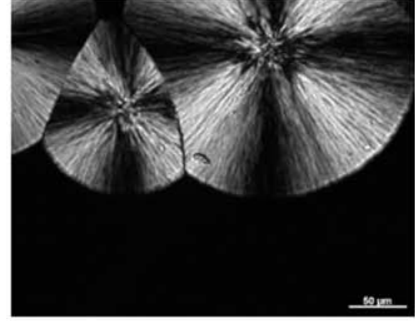

$T_{\text {iso }}=140^{\circ} \mathrm{C}, t_{\text {iso }}=30 \mathrm{~min}$

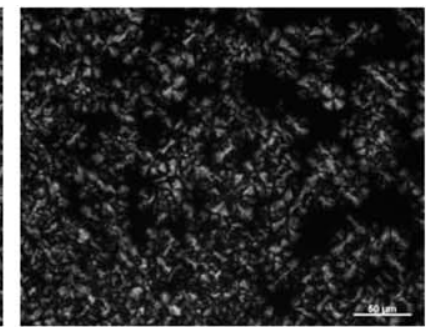

$T_{\text {iso }}=120^{\circ} \mathrm{C}, t_{\text {iso }}=3 \mathrm{~min}$

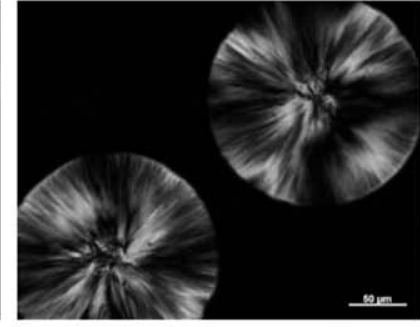

$T_{\text {iso }}=145^{\circ} \mathrm{C}, t_{\text {iso }}=30 \mathrm{~min}$

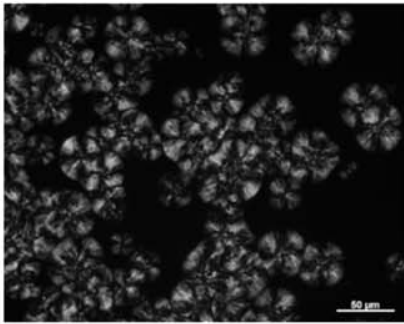

$T_{\text {iso }}=125^{\circ} \mathrm{C}, t_{\text {iso }}=5 \mathrm{~min}$

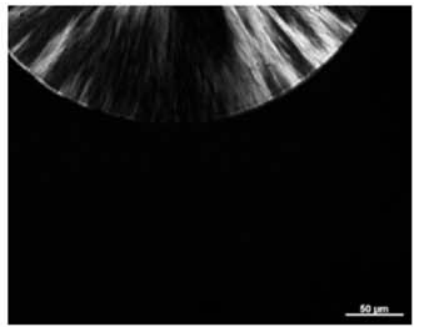

$T_{\text {iso }}=150{ }^{\circ} \mathrm{C}, t_{\text {iso }}=60 \mathrm{~min}$

Figure 2. Polarized optical micrographs of the PLLA homopolymer isothermally crystallized at various temperatures. The scale bar indicates $50 \mu \mathrm{m}$.

The Linkam JHT350 unit described previously was mounted between crossed polarizers. The scattering patterns were projected on a semitransparent polypropylene screen and recorded with a Hamamatsu C11440 camera, typically with 1-s intervals between the image acquisitions (acquisition time $=100 \mathrm{~ms}$ ). The images were processed with Fit2D, with which a radial integration of a scattering pattern was carried out. The integrated curves were then further processed with Matlab, with the application of a Lorentzian fit to follow the scattering vector $(\mathbf{q})$ value of the maximum scattering intensity versus the isothermal crystallization time $\left(t_{\text {iso }}\right)$.

A Rigaku 1D diffractometer was used for one-dimensional wide-angle X-ray diffraction (1D WAXD) measurements; it was equipped with a $\mathrm{Cu} \mathrm{K} \alpha$ source $(\lambda=1.54 \AA)$, which was used to evaluate the crystal structure of the samples. The $d$-spacings of the $(110) /(200)$ reflections of the $\alpha$ - and $\alpha^{\prime}$-crystal forms were 5.309 and $5.405 \AA$, respectively. ${ }^{23}$ For each measurement, a sample that was crystallized between two glass cover slides had the top cover slide removed to expose the material directly to the incident beam. $\mathrm{Al}_{2} \mathrm{O}_{3}$ powder was added next to the sample as a calibrant so that we could correct for slight alignment variations when changing samples.

With DSC, we studied whether the addition of PDLA had an effect on the dimensionality of crystal growth of PLLA. Samples of $1-4 \mathrm{mg}$ in hermetically sealed aluminum pans were isothermally crystallized with a temperature protocol similar to that of the POM/SALS experiments with the Linkam JHT350. The protocol was similar, as the DSC apparatus was incapable of achieving the near-instantaneous cooling rates of the Linkam unit. Instead, the cooling rate was programmed to be as high as possible; in practice, this resulted in controlled cooling rates of approximately $50^{\circ} \mathrm{C} / \mathrm{min}$. For this reason, only relatively low undercoolings were chosen to prevent the onset of crystalliza-

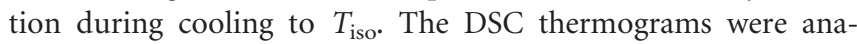
lyzed with TA Universal Analysis software. Avrami analysis was applied to the collected data to determine the dimensionality parameters.

\section{RESULTS AND DISCUSSION}

The results and discussion are presented according the temperature range of the isothermal crystallization experiments, which were divided in two parts. First, crystallization at low undercooling temperatures was investigated with POM measurements, with some emphasis on the observed lamellar twisting of PLLA. Second, crystallization at higher undercooling temperatures was studied with SALS experiments, after which the results from both experimental methods were combined and supported with 1D WAXD measurements. Finally, an Avrami analysis was performed on all of materials to calculate the dimensionality parameters.

\section{Optical Microscopy}

The nucleation and crystal growth kinetics of the selected PLA materials were first studied with POM. By taking images at set intervals (typically $10 \mathrm{~s}$ ), we could easily follow the spherulitic growth rates at various $T_{\text {iso }}$ values. Snapshots taken toward the end of crystallization for each material from these experiments are shown in Figures 2-4.

From these images, we could already make a few qualitative statements about PLA crystallization. For each material, it was evident that a higher $N$ was observed when $T_{\text {iso }}$ decreased. Similarly, less time was needed to achieve near-complete crystallization with decreasing temperature. The nucleating effect of the addition of stereocomplex PLA was evidenced by the much larger number of spherulites present at equal $T_{\text {iso }}$ values for the nucleated homopolymer with respect to the nonnucleated homopolymer (Figures 3 and 2, respectively). Furthermore, the differences in the growth rates between PLLA and the PLA copolymer could also be seen from the shorter isothermal time toward complete crystallization at equal temperatures (Figures 2 and 4 , respectively). 


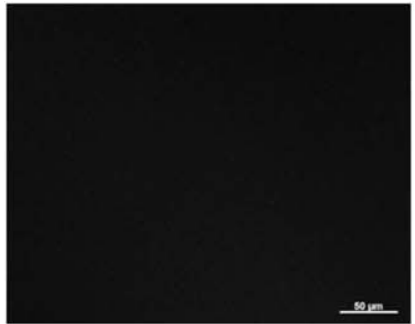

$T_{\text {iso }}=90^{\circ} \mathrm{C}, t_{\text {iso }}=3 \mathrm{~min}$

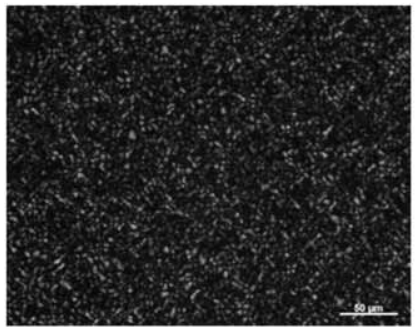

$T_{\text {iso }}=110^{\circ} \mathrm{C}, t_{\text {iso }}=3 \mathrm{~min}$

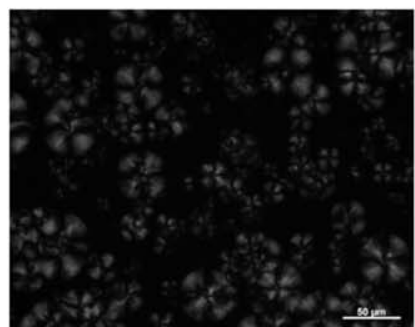

$T_{\text {iso }}=130{ }^{\circ} \mathrm{C}, t_{\text {iso }}=5 \mathrm{~min}$

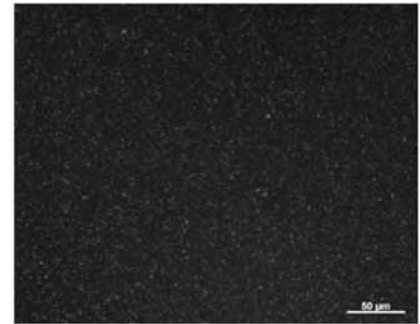

$T_{\text {iso }}=95^{\circ} \mathrm{C}, t_{\text {iso }}=3 \mathrm{~min}$

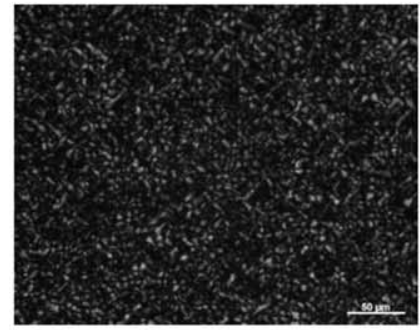

$T_{\text {iso }}=115^{\circ} \mathrm{C}, t_{\text {iso }}=3 \mathrm{~min}$

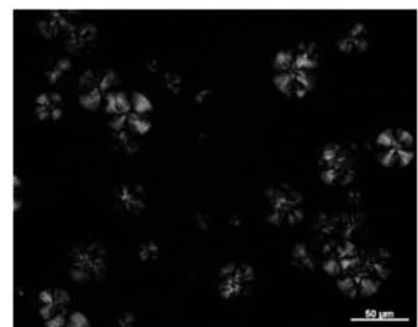

$T_{\text {iso }}=140^{\circ} \mathrm{C}, t_{\text {iso }}=5 \mathrm{~min}$

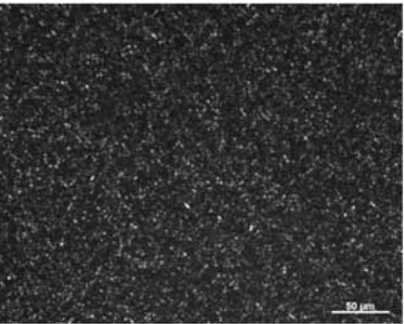

$T_{\text {iso }}=100^{\circ} \mathrm{C}, t_{\text {iso }}=3 \mathrm{~min}$

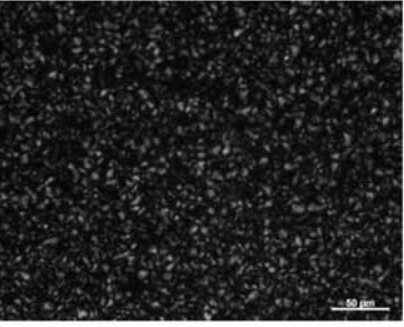

$T_{\text {iso }}=120^{\circ} \mathrm{C}, t_{\text {iso }}=3 \mathrm{~min}$

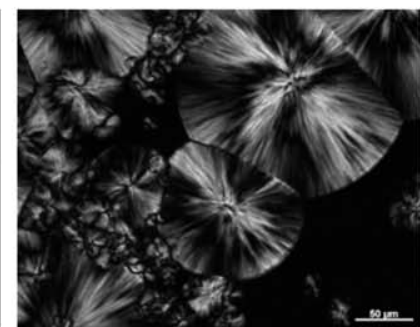

$T_{\text {iso }}=150^{\circ} \mathrm{C}, t_{\text {iso }}=30 \mathrm{~min}$

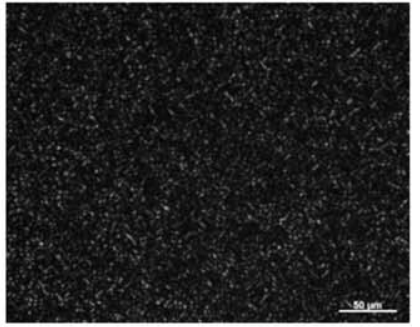

$T_{\text {iso }}=105^{\circ} \mathrm{C}, t_{\text {iso }}=3 \mathrm{~min}$

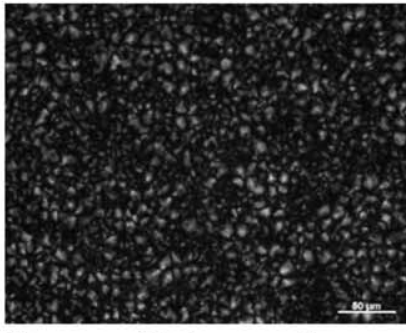

$T_{\text {iso }}=125^{\circ} \mathrm{C}, t_{\text {iso }}=5 \mathrm{~min}$

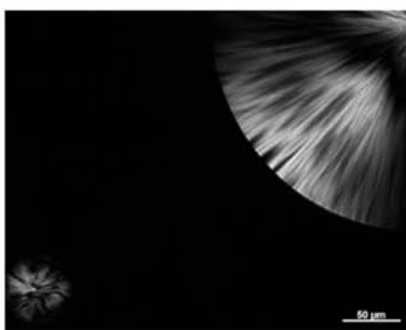

$T_{\text {iso }}=160^{\circ} \mathrm{C}, t_{\text {iso }}=90 \mathrm{~min}$

Figure 3. Polarized optical micrographs of the PLLA/1 wt \% PDLA blend isothermally crystallized at various temperatures. The scale bar indicates $50 \mu \mathrm{m}$.

\section{Lamellar Twisting}

Polymer spherulites consist of chain-folded lamellae that are oriented in such a way that their surfaces are parallel to the radius of the spherulite. As these lamellae are formed, some surface stress is also generated, and this can cause the lamellae to twist slightly and reduce the total free energy of the system. Although the exact mechanism that drives this process is not fully understood, the generally accepted view is that the twisting phenomenon is caused by an unbalanced stress situation at the lamellar growth front. ${ }^{24-27}$

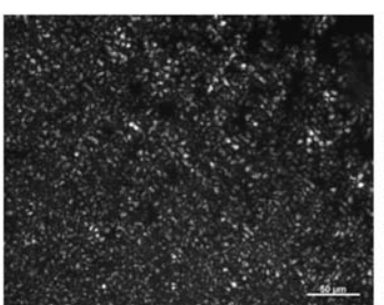

$T_{\text {iso }}=105^{\circ} \mathrm{C}, t_{\text {iso }}=30 \mathrm{~min}$

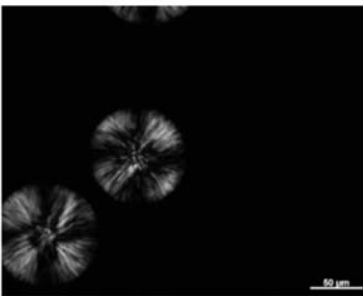

$T_{\text {iso }}=125^{\circ} \mathrm{C}, t_{\text {iso }}=90 \mathrm{~min}$

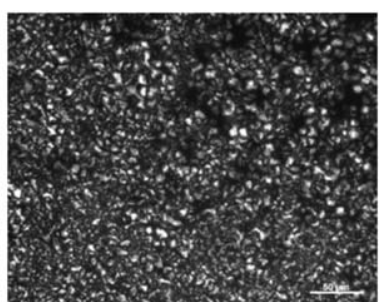

$T_{\text {iso }}=110^{\circ} \mathrm{C}, t_{\text {iso }}=30 \mathrm{~min}$

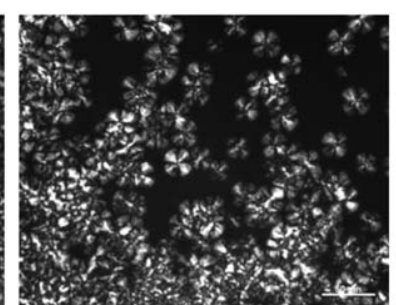

$T_{\text {iso }}=115^{\circ} \mathrm{C}, t_{\text {iso }}=60 \mathrm{~min}$

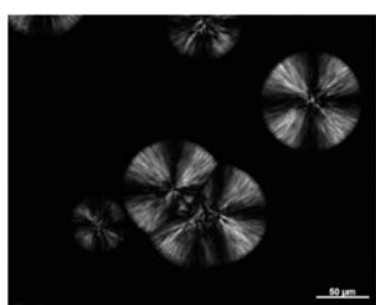

$T_{\text {iso }}=120^{\circ} \mathrm{C}, t_{\text {iso }}=90 \mathrm{~min}$

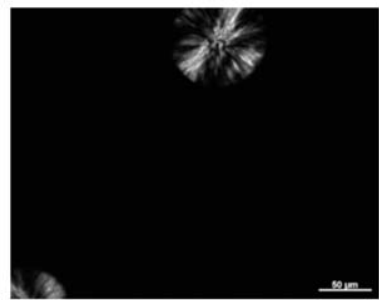

$T_{\text {iso }}=130^{\circ} \mathrm{C}, t_{\text {iso }}=90 \mathrm{~min}$

Figure 4. Polarized optical micrographs of the PLA copolymer isothermally crystallized at various temperatures. The scale bar indicates $50 \mu \mathrm{m}$. 


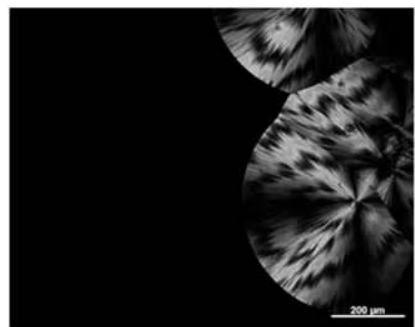

$T_{\text {iso }}=142.5^{\circ} \mathrm{C}, t_{\text {iso }}=70 \mathrm{~min}$

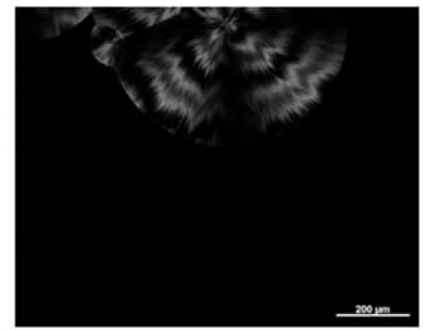

$T_{\text {iso }}=144^{\circ} \mathrm{C}, t_{\text {iso }}=70 \mathrm{~min}$

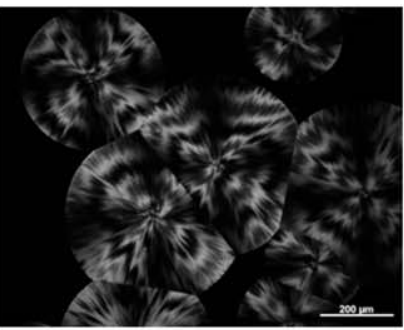

$T_{\text {iso }}=145^{\circ} \mathrm{C}, t_{\text {iso }}=70 \mathrm{~min}$

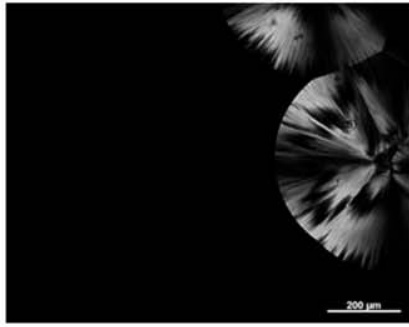

$T_{\text {iso }}=147^{\circ} \mathrm{C}, t_{\text {iso }}=70 \mathrm{~min}$

Figure 5. Polarized optical micrographs of the PLLA homopolymer isothermally crystallized at various temperatures at which lamellar twisting could be observed. The scale bar indicates $200 \mu \mathrm{m}$.

Hints of lamellar twisting, expressed as periodic extinction bands, were observed in POM experiments when PLLA was crystallized at low undercooling temperatures, as shown in Figure 2 . We then studied this phenomenon more closely by taking $1-2{ }^{\circ} \mathrm{C}$ temperature intervals between $140-150{ }^{\circ} \mathrm{C}$, where the PLLA homopolymer showed the clearest indication of these extinction bands. The most uniform lamellar twisting for this material was observed at a crystallization temperature of $144^{\circ} \mathrm{C}$, with a pitch of approximately $150-200 \mu \mathrm{m}$, as shown in Figure 5. More disordered banded patterns were observed within a small window centered around this temperature.

From the images taken at regular intervals, we found that it was possible to extract a linear growth rate by following the evolution of a spherulite boundary as a function of time. With known sample thickness and magnification, we found that it was also fairly straightforward to calculate an average $N$ by counting the number of spherulites toward the end of crystallization.

\section{SMALL-ANGLE LIGHT SCATTERING}

However, at temperatures below $120^{\circ} \mathrm{C}, \mathrm{N}$ increased to a point where the spherulites became so numerous that they could no longer be counted accurately and the extraction of the growth rate became equally problematic. For this reason, SALS was used because this technique yielded information about the average size, shape, and internal order of the spherulites even when these scattering bodies were too small to be characterized with optical microscopy. The use of the same Linkam JHT350 in this setup provided the means to investigate the lower temperature range and still maintain the near-instantaneous cooling and prevent the onset of crystallization during this step.

The following expression describes the Rayleigh scattering of the perpendicularly polarized light of films with space-filling spherulitic structures ${ }^{28}$ :

$$
\begin{aligned}
& R_{H v}=\frac{16 \pi^{4}}{\lambda_{0}^{4}} \phi_{s} V_{s} \cos ^{2} \rho_{2}\left(\frac{3}{\mathbf{U}^{3}}\right)^{2} \\
& {\left[\left(\alpha_{r}-\alpha_{t}\right) \frac{\cos ^{2} \theta / 2}{\cos \theta} \sin 2 \mu(4 \sin \mathbf{U}-\mathbf{U} \cos \mathbf{U}-3 \cos \mathbf{U})\right]^{2}} \\
& \times[\kappa(\theta, \mu) F(\theta, \mu)]^{-1}
\end{aligned}
$$

where $R_{H v}$ is the scattering intensity under perpendicular polarizers normalized according to the criteria for the Rayleigh ratio. We achieved this by keeping the scattering volume, that is, the sample volume, the intensity of the incident laser beam, and the distance between the sample and the screen constant for all measurements. $\lambda_{0}$ is the wavelength of light in vacuo, $\phi_{s}$ is the volume fraction of spherulites, and $V_{s}$ is the volume of the spherulite. The $\cos \rho_{2}$ function depends on the radial scattering angle $(\theta)$ and azimuthal scattering angle $(\mu)$ and approaches unity when these are small. $\alpha_{r}$ and $\alpha_{t}$ are the radial and tangential polarizabilities of the spherulite, respectively. $\kappa(\theta, \mu)$ and $F(\theta, \mu)$ are correction factors, the first for multiple scattering and the latter for disorder and truncation. $\mathbf{U}$ is the reduced scattering vector and is defined as follows:

$$
\mathbf{U}=r_{s} \frac{4 \pi n_{m}}{\lambda_{0}} \sin \left(\frac{\theta}{2}\right)=\mathbf{q} r_{s}
$$

This equation relates $\mathbf{q}$ to the spherulite radius $\left(r_{s}\right)$, where $n_{m}$ is the refractive index of the media containing the scattering entities, for example, PLA. At a $\mu$ where a scattering lobe has a maximum [typically $45^{\circ}$, related to the $\sin 2 \mu$ term in eq. (1)], $\mathbf{U}$ is equal to 4.09 when perfect spherulitic growth is assumed; this, in turn, simplifies the expression for the average spherulite radius $\left(r_{s, \text { avg }}\right)$ to

$$
r_{s, \text { avg }}=\frac{4.09 \lambda_{0}}{4 \pi n_{m} \sin \left(\theta_{\max } / 2\right)}=\frac{4.09}{\mathbf{q}}
$$

$\theta_{\max }=$ the radial scattering angle where the scattering intensity has a maximum.

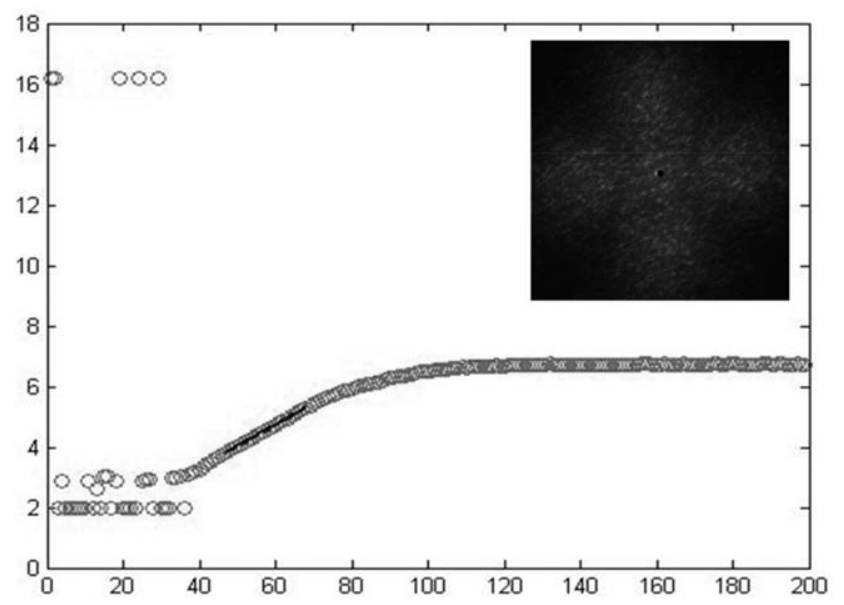

Figure 6. $r_{s, a v g}(\mu \mathrm{m}$; vertical axis) versus time ( $s$; horizontal axis) for PLLA $/ 1 \%$ PDLA crystallized at $100^{\circ} \mathrm{C}$. A tangent line is fitted in the linear growth regime, the slope of which is $G$. The inset image is a typical SALS pattern showing the cloverlike scattering lobes. 


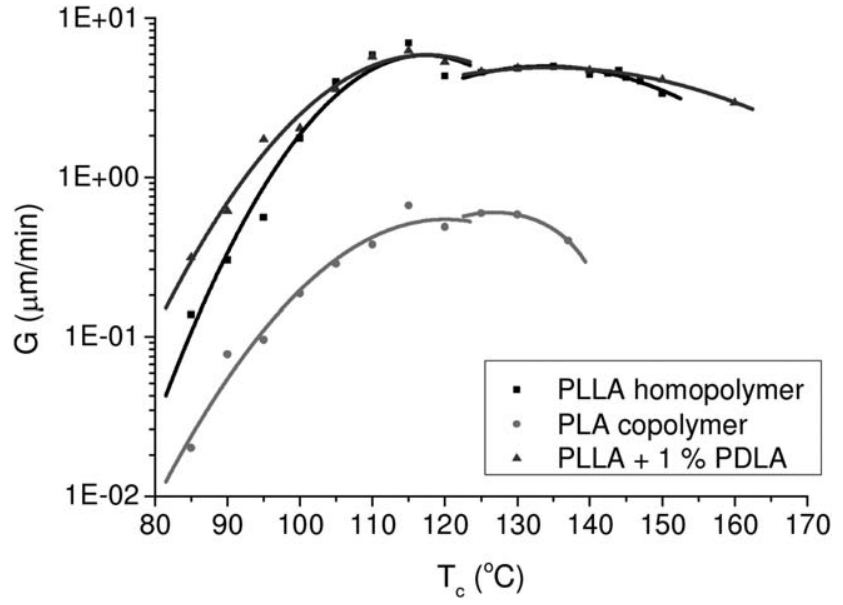

Figure 7. $G$ as a function of the isothermal crystallization temperature (here $T_{c}$ ) for the studied PLA materials. The solid lines are the secondorder polynomial fitting curves.

Thus, the use of SALS to follow the evolution of the maximum $\mathbf{q}$ in time under isothermal crystallization conditions allows for the easy calculation of $r_{s, \text { avg }}$ via eq. (3). The plotting of $r_{s, \text { avg }}$ as a function of $t_{\text {iso, }}$, as shown in Figure 6, enables the calculation of $G$ through the fitting of a tangent line in the linear growth regime.

Again, with the assumption of perfect spherulitic growth, it is possible to calculate $N$ with the Kolmogorov-Avrami-Evans equation $^{29-31}$ :

$$
\phi=1-\exp \left(-\frac{4}{3} \pi N G^{3} t^{3}\right)
$$

where $\phi$ is the crystal volume fraction and $t$ is time. Equation (4) can be rewritten to obtain an expression for $N$ :

$$
N=-\frac{\ln (1-\phi)}{\frac{4}{3} \pi G^{3} t^{3}}
$$

At half space filling $(\phi=0.5)$, still in the linear growth regime, and with $r_{s, \text { avg }}$ taken as Gt, eq. (5) becomes

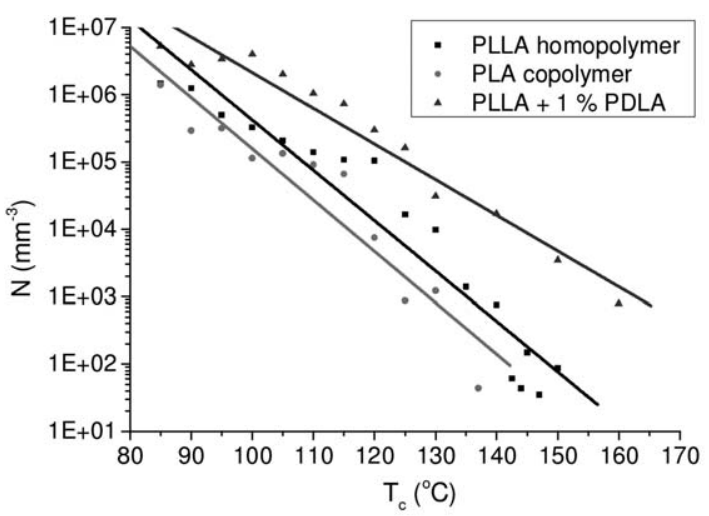

(a)

$$
N=-\frac{\ln 0.5}{\frac{4}{3} \pi r_{1 / 2}^{3}}
$$

where $r_{1 / 2}$ is the average spherulite radius at half space filling. The results from these calculations are discussed in the next section.

\section{Growth Rates and Ns}

Finally, the growth rates and Ns obtained in both the POM and SALS experiments, covering a wide range of $T_{\text {iso }}$ values, are combined in Figures 7 and 8. The values of $G$ and $N$ at $120^{\circ} \mathrm{C}$ were determined with both methods and were found to be in close agreement; therefore, they were averaged for clarity in their respective plots. Low undercoolings (up to $10^{\circ} \mathrm{C}$ below $T_{m}$ ) were not investigated because of the very long crystallization times required; these might have made degradation a considerable factor during the length of the experiment.

It was evident that the addition of PDLA to the homopolymer to form stereocomplex PLA as a nucleating agent hardly affected the $G$ value of PLLA. However, as expected, it did have a significant effect on $N$; that is, an increase of approximately one order of magnitude was observed. $N$ of the copolymer did not vary greatly from that of the homopolymer, but its $G$ was about one order of magnitude lower because of the presence of randomly distributed D-lactic acid units along the backbone. This affected the material's ability to form neatly folded chain crystals.

Furthermore, both the nucleated and nonnucleated PLLA showed two distinct growth regimes, despite the little difference in morphology observed in the POM images in that particular temperature region. In the literature, the appearance of such double bell-shaped curves was ascribed to PLA crystallizing in two different crystal forms: the $\alpha$ form for low undercoolings and the $\alpha^{\prime}$ form for higher undercoolings. The transition temperature between both regimes was reported to be around $120^{\circ} \mathrm{C} .{ }^{32-34}$

In this study, the transition was corroborated by 1D WAXD measurements. The measured $d$-spacings of the strong (110)/ (200) reflection for materials crystallized at various temperatures are indicated in Table I.

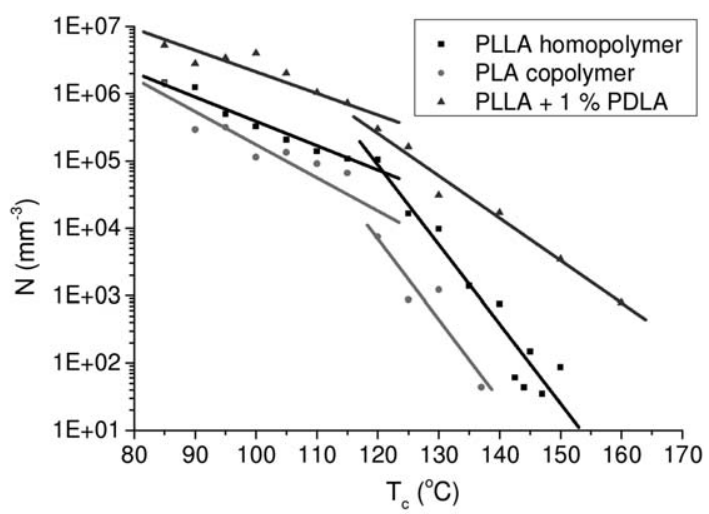

(b)

Figure 8. $N$ as a function of the isothermal crystallization temperature (here $T_{c}$ ) for the studied PLA materials. The solid lines are the (a) linear fits and (b) separate linear fits below and above $120^{\circ} \mathrm{C}$. 
Table I. 1D WAXD Results for All of the Studied PLA Materials

\begin{tabular}{llll}
\hline & \multicolumn{3}{c}{$d$-spacing of the $(110) /(200)$} \\
\hline & $\begin{array}{l}\text { PLLA } \\
\text { homopolymer }\end{array}$ & $\begin{array}{l}\text { PLA } \\
\text { copolymer }\end{array}$ & $\begin{array}{l}\text { PLLA } \\
1 \% \text { PDLA }\end{array}$ \\
\hline$T_{\text {iso }}\left({ }^{\circ} \mathrm{C}\right)$ & 5.419 & 5.402 & 5.383 \\
115 & 5.418 & 5.415 & 5.311 \\
120 & 5.337 & 5.351 & 5.338 \\
125 & 5.348 & 5.323 & 5.315 \\
\hline
\end{tabular}

Decreases in the measured $d$-spacing of more than $0.05 \AA$, indicative of the $\alpha-\alpha^{\prime}$ transition, were observed for both PLLA and the PLA copolymer between 120 and $125^{\circ} \mathrm{C}$. Interestingly, the transition for the nucleated homopolymer appeared to occur between 115 and $120^{\circ} \mathrm{C}$. Although this suggested that the presence of the stereocomplex PLA altered the $\alpha-\alpha^{\prime}$ transition temperature by a few degrees, it was more likely that this variation was simply due to experimental error. It seems unlikely that the growth mechanism would be affected by a nucleating agent.

The transitions for each material are reflected in Figure 7 by two separate fitting curves for the $G$ data. A similar feature was observed in the $N$ data, where separate linear fits below and above the transition temperature yielded different slopes, as shown in Figure 8(b). This implied that the $\alpha$ and $\alpha^{\prime}$ forms nucleated from different nuclei. However, direct evidence was lacking, and more research is required to support this idea.

\section{Avrami Analysis}

The PLLA homopolymer crystallized in a spherulitic morphology or, in the case of very low undercooling temperatures, as hexagonal lamellar crystals. ${ }^{32}$ However, the stereocomplex PLA was found to form disordered spherulites or even adopt a disklike or platelike geometry when it crystallized from nonequimolar amounts of the enantiomers. ${ }^{35-37}$ Therefore, we investigated whether the presence of the stereocomplex PLA affected the dimensionality of the homopolymer crystal growth.

Therefore, isothermal crystallization experiments with nucleated and nonnucleated PLLA samples were carried out with DSC at 150,140 , and $130^{\circ} \mathrm{C}$. Lower temperatures could not be studied as the crystallization had already started during quenching to the programmed crystallization temperature. For similar reasons, the $T_{\text {iso }}$ values chosen for the PLA copolymer were 130, 125 , and $120^{\circ} \mathrm{C}$.

With the TA Universal Analysis software, a running integral was performed over the crystallization exotherm to calculate the crystallization enthalpy for each point in time. These enthalpies were normalized to the final (maximum) enthalpy for each experiment to yield normalized crystallinity values $\left(X_{n r m} \mathrm{~s}\right)$. Avrami analysis was then carried out on these data.

Avrami theory is expressed in eq. $(7)^{30}$ :

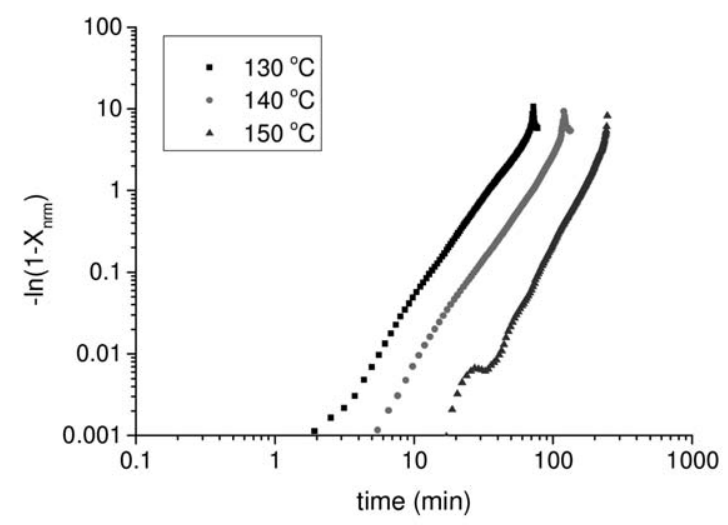

(a)

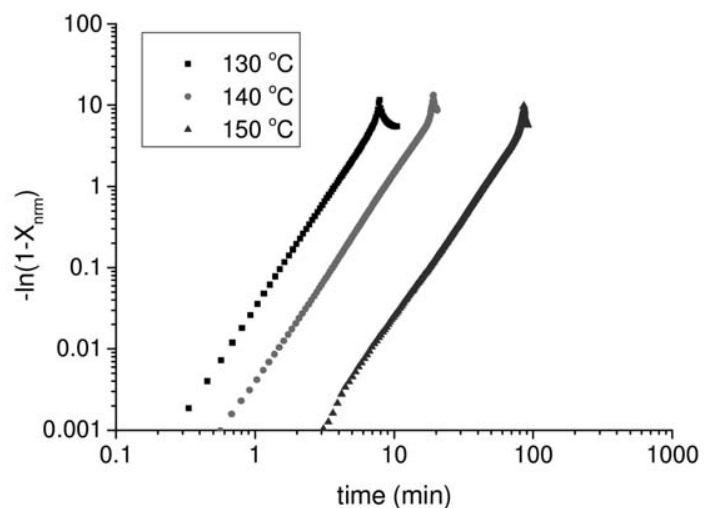

(b)

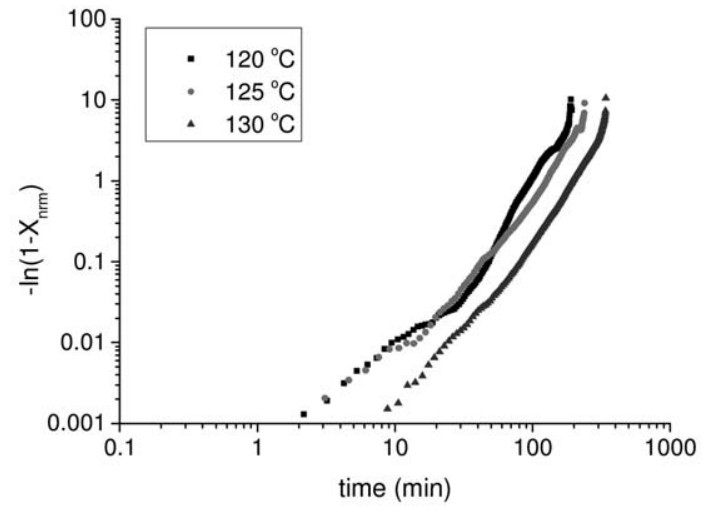

(c)

Figure 9. Avrami plots for the (a) PLLA homopolymer, (b) PLLA/1 wt \% PDLA, and (c) PLA random copolymer. 
Table II. $n$ and $K$ Values for the Studied PLA Materials

\begin{tabular}{|c|c|c|c|c|c|}
\hline Material & $T_{\text {iso }}\left({ }^{\circ} \mathrm{C}\right)$ & \multicolumn{2}{|c|}{$n$} & \multicolumn{2}{|c|}{$-\log K\left(\min ^{-n}\right)$} \\
\hline PLLA homopolymer & 130 & \multicolumn{2}{|c|}{2.67} & \multicolumn{2}{|c|}{4.60} \\
\hline & 140 & \multicolumn{2}{|c|}{2.76} & \multicolumn{2}{|c|}{5.37} \\
\hline & 150 & \multicolumn{2}{|c|}{3.30} & \multicolumn{2}{|c|}{7.46} \\
\hline \multirow[t]{3}{*}{ PLLA + 1\% PDLA } & 130 & \multicolumn{2}{|c|}{2.63} & \multicolumn{2}{|c|}{1.84} \\
\hline & 140 & \multicolumn{2}{|c|}{2.59} & \multicolumn{2}{|c|}{2.71} \\
\hline & 150 & \multicolumn{2}{|c|}{2.63} & \multicolumn{2}{|c|}{4.41} \\
\hline \multirow[t]{3}{*}{ PLA copolymer } & 120 & 1.39 & 3.17 & 6.29 & 3.38 \\
\hline & 125 & 1.33 & 2.46 & 5.15 & 3.36 \\
\hline & 130 & 1.85 & 2.66 & 6.10 & 4.58 \\
\hline
\end{tabular}

The columns are split for the PLA copolymer values because two regimes could be distinguished. The first column for $\mathrm{n}$ corresponds to the first column for $-\log K$.

$$
X_{n r m}=1-\exp \left(-K t^{n}\right)
$$

where $K$ is the kinetic rate constant and $n$ is the Avrami exponent, which contains information related to the nucleation mechanism, the dimensionality of crystal growth, and the growth mechanism. Typically, the value of $n$ is between 2 and 4 for polymer crystallization. Higher values of $n$ are associated with three-dimensional spherulitic growth with the (predominantly) sporadic nucleation of thermal nuclei, whereas lower values are attributed to two-dimensional growth with the (mainly) instantaneous nucleation of athermal nuclei. ${ }^{38}$

Equation (7) can be rewritten as follows:

$$
\log \left[-\ln \left(1-X_{n r m}\right)\right]=\log K+n \log t
$$

The Avrami plots obtained in this way are shown in Figure 9. The use of eq. (8) allows easy extraction of the $\log K$ and $n$ parameters from a linear fit, which are represented as the intercept and slope values, respectively. These values are reported in Table II.

All of the values of $n$ that we found for the neat and nucleated PLLA were approximately 3 ; this indicated that the crystal growth was three-dimensional and athermal. On average, the values for the nucleated PLLA seemed slightly lower, but when compared to similar studies from literature, all of the reported values ranged from 2.4 to 3.3 for both neat and PDLAnucleated PLLA. ${ }^{19,33,39,40}$ Tsuji and coworkers examined the effect of the PDLA content in even more detail and observed no significant effect on the $n$ parameter.

Moreover, it should be noted that the determination of the crystallization onset time $\left(t_{0}\right)$ can sometimes be inaccurate, and as such, this can affect the value of the $n$ parameter. To study this effect, eq. (8) can be modified to include a certain initial crystallinity $\left(X_{0}\right)$ :

$$
\log \left[-\ln \left(\frac{1-X_{n r m}}{1-X_{0}}\right)\right]=\log K+n \log t
$$

Although it seemed unlikely for the neat homopolymer to have any $X_{0}$ because of the length of the crystallization step (which already required more than $1 \mathrm{~h}$ at the lowest $T_{\text {iso }}$ ), it was plausible for the nucleated PLLA. This would mean the $n$ values reported for this material were slightly underestimated. We used eq. (9), filling in values for $X_{0}$ up to 0.05 and fitting the data for the nucleated PLLA, and it yielded $n$ values around 2.90, which were no longer significantly different than those found for the neat homopolymer.

As shown in Table II, two values of $n$ were observed for the PLA copolymer because two different slopes could be fitted to the graphs of this material in the Avrami plots shown in Figure 8. The transition between these regimes occurred around $t=40 \mathrm{~min}$ at 120 and $125^{\circ} \mathrm{C}$, whereas the transition at $130^{\circ} \mathrm{C}$ occurred around $t=70 \mathrm{~min}$. This observation suggested that the PLA copolymer crystallites appeared to have a preferred orientation initially, and later, a transition into spherulitic growth took place. From well-established studies on spherulite formation, it is known that at the very beginning of crystallization, polymer chains may adopt a sheaflike conformation, from which crystallization proceeds in a more isotropic manner. ${ }^{41,42}$ It seemed reasonable that the observed transition for the PLA copolymer corresponded to these initial stages of spherulite formation because of its very low growth rate. This enabled the detection of this circumstance.

\section{CONCLUSIONS}

The spread of reported literature values for the crystallization kinetics of PLA may negatively affect subsequent modeling studies. Therefore, the crystallization behavior of a PLLA homopolymer, a PLA random copolymer, and PLLA blended with 1 wt \% PDLA (yielding stereocomplex PLA to act as a nucleating agent) were studied in quiescent conditions with POM and SALS experiments. The Gs and Ns were determined for these materials over a wide range of $T_{\text {iso }}$ values between $T_{g}$ and $T_{m}$ with a Linkam dual-hot-stage device to provide near-instantaneous cooling. Two distinct growth rate regimes were observed for all of materials; these were attributed to them crystallizing into an $\alpha$ and $\alpha^{\prime}$ forms. This $\alpha-\alpha^{\prime}$ transition was found to occur around $120^{\circ} \mathrm{C}$, and this was corroborated with 1D WAXD measurements. Moreover, when we considered the experimental nucleation data with this transition in mind, there was also a strong indication that for $N$, these two regimes should be taken 
into account. Indeed, through the application of separate linear fits for the two regimes, a better description of the nucleation data was obtained. This result suggested that the $\alpha$ - and $\alpha^{\prime}$ form nucleated from different nuclei. However, more research is required to support this idea.

Furthermore, the dimensionality of the crystal growth was studied for both nucleated and nonnucleated PLLA and was calculated to be approximately 3; this was in accordance with reported literature values and indicated that the homopolymer crystal growth was three-dimensional and was not affected by the presence of the stereocomplex PLA, which acted as a nucleating agent. The PLA copolymer showed a transition of the dimensionality parameter from roughly 1.5 to about 2.8 after 40-70 min; this was ascribed to a very slow spherulite formation process, where the crystals initially adopted a sheaflike conformation before they continued to grow isotropically.

Moreover, lamellar twisting of the PLLA homopolymer was studied and was found to be most prominent at a $T_{\text {iso }}$ value of $144^{\circ} \mathrm{C}$.

With this study, we obtained valuable data, which can be used for future modeling studies to enable predictions of material behavior in various industrial processes.

\section{ACKNOWLEDGMENTS}

This work was part of the Biobased Performance Materials Research Programme (project BPM-130 PLA StIC) and was financially supported by the Dutch Ministry of Economic Affairs, Agriculture, and Innovation. The authors are grateful to Gerald Schennink of the Food and Biobased Research Institute in Wageningen for the preparation of the PLLA/1 wt \% PDLA compound.

\section{REFERENCES}

1. Ahmed, J.; Varshney, S. K. Int. J. Food Properties 2011, 14, 37.

2. Auras, R.; Harte, B.; Selke, S. Macromol. Biosci. 2004, 4, 835.

3. Davachi, S. M.; Kaffashi, B. Polym. Plast. Technol. Eng. 2015, 54, 944.

4. Kopinke, F.-D.; Remmler, M.; Mackenzie, K.; Möder, M.; Wachsen, O. Polym. Degrad. Stab. 1996, 53, 329.

5. Ramkumar, D. H. S.; Bhattacharya, M. Polym. Eng. Sci. 1998, 38, 1426.

6. Li, H. B.; Huneault, M. A. Polymer 2007, 48, 6855.

7. Nakajima, H.; Takahashi, M.; Kimura, Y. Macromol. Mater. Eng. 2010, 295, 460.

8. Wen, L.; Xin, Z. Chin. J. Chem. Eng. 2010, 18, 899.

9. Kokturk, G.; Serhatkulu, T. F.; Cakmak, M.; Piskin, E. Polym. Eng. Sci. 2002, 42, 1619.

10. Ma, P.; Hristova-Bogaerds, D. G.; Schmit, P.; Goossens, J. G. P.; Lemstra, P. J. Polym. Int. 2012, 61, 1284.

11. Liu, H.; Zhang, J. J. Polym. Sci. Part B: Polym. Phys. 2011, 49, 1051 .
12. Piorkowska, E.; Kulinski, Z.; Galeski, A.; Masirek, R. Polymer 2006, 47, 7178.

13. De Santis, P.; Kovacs, A. J. Biopolymers 1968, 6, 299.

14. Hoogsteen, W.; Postema, A. R.; Pennings, A. J.; Ten Brinke, G.; Zugenmaier, P. Macromolecules 1990, 23, 634.

15. Cartier, L.; Okihara, T.; Ikada, Y.; Tsuji, H.; Puiggali, J.; Lotz, B. Polymer 2000, 41, 8909.

16. Stoclet, G.; Seguela, R.; Lefebvre, J. M.; Elkoun, S.; Vanmansart, C. Macromolecules 2010, 43, 1488.

17. Garlotta, D. J. Polym. Environ. 2001, 9, 63.

18. Ikada, Y.; Jamshidi, K.; Tsuji, H.; Hyon, S. H. Macromolecules 1987, 20, 904.

19. Tsuji, H.; Takai, H.; Saha, S. K. Polymer 2006, 47, 3826.

20. Rahman, N.; Kawai, T.; Matsuba, G.; Nishida, K.; Kanaya, T.; Watanabe, H.; Okamoto, H.; Kato, M.; Usuki, A.; Matsuda, M.; Nakajima, K.; Honma, N. Macromolecules 2009, 42, 4739.

21. Saeidlou, S.; Huneault, M. A.; Li, H.; Park, C. B. Prog. Polym. Sci. 2012, 37, 1657.

22. Vasanthakumari, R.; Pennings, A. J. Polymer 1983, 24, 175.

23. Zhang, J.; Duan, Y.; Sato, H.; Tsuji, H.; Noda, I.; Yan, S.; Ozaki, Y. Macromolecules 2005, 38, 8012.

24. Keith, H. D.; Padden, F. J. Macromolecules 1996, 29, 7776.

25. Lotz, B.; Cheng, S. Z. D. Polymer 2005, 46, 577.

26. Xu, J.; Guo, B.-H.; Zhou, J.-J.; Li, L.; Wu, J.; Kowalczuk, M. Polymer 2005, 46, 9176.

27. Maillard, D.; Prud'homme, R. E. Macromolecules 2008, 41, 1705.

28. Stein, R. S.; Misra, A.; Yuasa, T.; Khambatta, F. Pure Appl. Chem. 1977, 49, 915.

29. Kolmogorov, A. N. Bull. Acad. Sci. USSR Math. Ser. 1937, 1, 355.

30. Avrami, M. J. Chem. Phys. 1940, 8, 212.

31. Evans, U. Trans. Faraday Soc. 1945, 41, 365.

32. Abe, H.; Kikkawa, Y.; Inoue, Y.; Doi, Y. Biomacromolecules 2001, 2, 1007.

33. Iannace, S.; Nicolais, L. J. Appl. Polym. Sci. 1997, 64, 911.

34. Tsuji, H.; Tezuka, Y.; Saha, S. K.; Suzuki, M.; Itsuno, S. Polymer 2005, 46, 4917.

35. Tsuji, H.; Ikada, Y. Macromolecules 1993, 26, 6918.

36. Tsuji, H. Macromol. Biosci. 2005, 5, 569.

37. Okihara, T.; Tsuji, M.; Kawaguchi, A.; Katayama, K.-I.; Tsuji, H.; Hyon, S.-H.; Ikada, Y. J. Macromol. Sci. Phys. 1991, 30, 119.

38. Van Krevelen, D. W.; Te Nijenhuis, K. Properties of Polymers; Elsevier: Amsterdam, 1990.

39. Kolstad, J. J. J. Appl. Polym. Sci. 1996, 62, 1079.

40. Miyata, T.; Masuko, T. Polymer 1998, 39, 5515.

41. Keller, A.; Waring, J. R. S. J. Polym. Sci. 1955, 17, 447.

42. Inoue, M. J. Polym. Sci. 1961, 55, 443. 